\title{
Role of Aphytis lepidosaphes Compere, 1955 (Hymenoptera Aphelinidae) in limiting Lepidosaphes beckii (Newman, 1869) (Homoptera Diaspididae) populations in an orange orchard in Rouiba (Algeria)
}

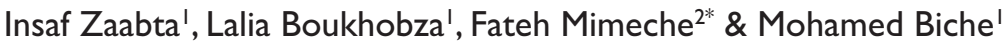 \\ 'National Superior School of Agronomy 16200 El Harrach Algiers, Algeria \\ ${ }^{2}$ Department of Agricultural Sciences, University of M'Sila, BP 166 Echbilia, 28000 M'Sila, Algeria \\ ${ }^{*}$ Corresponding author, email: mimechefateh@gmail.com
}

\begin{abstract}
This work highlights the study of Lepidosaphes beckii (Newman, 1869) (Homoptera Diaspididae) population dynamics as well as the impact of its external parasite Aphytis lepidosaphes Compere, 1955 (Hymenoptera Aphelinidae) in an orange orchard in Rouiba (Algeria). A year period study shows that $L$. beckii has three generations per year: the first is the autumnal generation; the second is through the spring and the third throughout summer. Moreover, this cochineal presents a very strong affinity for the central part of the trees and the lower side of the tree leaves which offers optimal conditions for its development. Aphytis lepidosaphes also develops three generations per year: in autumn, spring and summer, matching perfectly the three generations of its host. The parasite can be found where its host is abundant (plentiful). The global parasitism rate records is $22.54 \%$ for $L$. beckii, this rate remains weak to control the cochineal populations.
\end{abstract}

KEY WORDS Aphytis lepidosaphes; Citrus; Lepidosaphes beckii; Parasitic incidence; Parasitoid.

Received 24.09.2019; accepted 15.02.2020; published online 25.02.2020

\section{INTRODUCTION}

The Insecta belongs to the Coccoidea superfamily, which is divided into 23 families and 7700 species (Sforza, 2008) distributed throughout the world and more particularly in the southern hemisphere. These species are not all crop pests. Some are used in the daily life of humans and considered useful insects (Kreiter et al., 1998). However, three families cause major economic damage in the world: Coccidae, formerly known as lecanines, Pseudococcidae or mealybugs and Diaspididae or shielded mealybugs or diaspines. Lepidosaphes beckii (Newman, 1869) (Homoptera Diaspididae) constitute the most important pest of citrus fruits in Algeria. This insect is also considered a major pest of citrus in South Africa and Spain (Ben-Dov et al., 2014).

Indeed, biological control has very quickly been an effective way to fight mealybugs. It is one of the most effective given the sedentary nature of these pests (Foldi, 2003). In many geographical areas, the ectoparasitoid Aphytis lepidosaphes Compere, 1955 (Hymenoptera Aphelinidae) is reported as the most effective, natural enemy of $L$. beckii. In Florida, the parasitoid effectively controls cochineal populations at a parasitism rate of $50 \%$ (Stathas et al., 2015). The number of females in the parasite usu- 
ally exceeds that of males (Waterhouse \& Sands, 2001).

The study of this parasite allows us to have the opportunity to fight against this pest in order to improve yields and ensure a place among citrus producing countries.

\section{MATERIAL AND METHODS}

The study is conducted on a private farm in the Rouiba region $\left(36^{\circ} 44^{\prime} 00^{\prime \prime} \mathrm{N}\right.$ and $\left.3^{\circ} 17^{\prime} 00^{\prime \prime} \mathrm{E}\right)$. This region is located East of Mitidja $25 \mathrm{~km}$ from Algiers and $7 \mathrm{~km}$ from the Mediterranean Sea. This experiment started at the beginning of November 2014 and ended in August 2015.

The study orchard has an area of 1.5 ha consisting of 425 orange trees of Washingtonia variety navel planted in 1990. The procedure requires regular sampling over time. The method used is inspired by the work of Vasseur \& Schvester (1957). It consists of choosing 2 trees from which are taken 1 branch of $20 \mathrm{~cm}$ long and 2 leaves from each cardinal direction (North, South, East and West) and in the center of the tree. Then, these samples are placed differently in kraft paper bags on which all coordinates are mentioned (date, direction, etc.).

The twigs and leaves harvested are carefully examined under a binocular loupe. The different biological states of the mealybug are quantified and recorded on cards bearing the date of the release and the direction of sampling. For each stage we quantify the total number of live, dead and parasitized $L$. beckii individuals in order to assess the state of infestations and the evolution of its parasite A. lepidosaphes over time.

\section{RESULTS AND DISCUSSION}

\section{Overall evolution}

An overall examination of the fluctuations of the mealybug populations reveals the presence of three periods of intense activity: an autumnal period, a spring season and a summer season. The most important peaks are recorded during the spring and summer period. However, there are three very distinct peaks: the first peak at the beginning of January $(10.02 \%)$, the second during the month of
March (20.53\%) and the last during the month of June (27.97 \%) (Fig. 1).

The results obtained on the population dynamics of $L$. beckii during the period from 1 November 2014 to 10 August 2015 confirm the existence of three annual generations: an autumn generation, a spring generation and a summer generation. Zuniga (1971) reported three annual generations in northern Chile, two to three generations per year in the central region and only one annual generation in the southern region. On the other hand, in the Eastern Cape in South Africa, De Villiers (1998) reports four generations annually and Smirnoff (1960) found four generations a year in Morocco. The majority of authors agree to count from 2 to 5 generations, this figure varies according to the region's climate conditions chosen for the study and the smallest number of generation is observed in the countries where the rigor of the winter imposes a stoppage of development (Benassy, 1975).

\section{Cardinal distribution}

The results of figure 2 shows that the center orientation is most favored by this scale with a percentage of $35.99 \%$. This place seems to be a preferential place for this cochineal. Indeed, according to Fabres (1979), the influence of the thermohygrometric conditions of the shaded habitat on the rate of expansion of the cochineal are very favorable to the cochineal. The East of the tree comes in second place hosting $24.25 \%$ of the global population of the cochineal.

The spatial distribution of this species on the tree is closely related to the microclimate created within the tree. Moreover, the species have a marked preference for the center orientation of the tree. This place seems to give it favorable conditions for its optimal development. Moreover, this species shows in a remarkable way the lower face of the leaf.

\section{Distribution according to the plant organ}

The results reported in figure 3 show that the cochineal prefers to attach to the leaves and precisely on the underside with $46.32 \%$ against $41.17 \%$ on the upper face. This place offers cochineal favorable fixation conditions. Indeed, the blade of the leaf is of a very fine texture favoring 
the bites of opophagous insects. Avidov \& Harpaz (1969) noted that this cochineal prefers trees with thick foliage and settles more on leaves and fruits than on young branches. According to Fabres (1979), for the L. beckii scale, the leaves are the organs of choice.

\section{Ecology of Aphytis lepidosaphes}

We counted 99 eggs of the parasite throughout our study period. At the beginning of our sampling, eggs accounted for $30.16 \%$ of the global parasite population during the month of November. From this date, there is a gradual regression of eggs to disappear almost entirely during the winter period. As soon as atmospheric conditions become favorable again, we can see a recovery of the egg-laying, as it already is $3.85 \%$ as of February. Subsequently, the number of eggs gradually increases to $22.22 \%$ during the month of May and then decreases during the month of June. The oviposition of the parasite is once again taking place in August with 23.91\% (Fig. 4). In general, it is very rare to observe the eggs of A. lepidosaphes. Benassy (1961) reports that all Aphytis Howard, 1900 pierce the host's shield to deposit their eggs. This limitation is probably due to the difficulty of piercing the shield of some mealybugs.

The larvae of $A$. lepidosaphes are represented by young larvae and older larvae. Concerning the fluctuations of the young larvae, we note the presence of three peaks of populations: the first peak in November (44.44\%), the second in April (15.07\%) and the third in August (26.09\%) (Fig. 5). For older larvae, their rate varies between $88.46 \%$ and $100 \%$ during the month of December to February. Note that this stage represents the wintering stage of the parasitoid. From the beginning of April, there is a new increase of these larvae in the cochineal populations, and they reach their maximum in June with $48.24 \%$. From this date, their number will decrease more and more to reach their lowest rate during the month of August with 2.17\% (Fig. 6).

At the beginning of our sampling, nymphs are rarely present in cochineal populations. Indeed, they display only $7.94 \%$ during the month of November to disappear then completely the whole winter period. It is only from the month of February that they appear in the populations of its host where they display at this date $7.69 \%$ of the global population of the parasitoid. The highest rate is noted during the month of March with $44.11 \%$. There is then a gradual decrease in numbers of these larvae to reach their lowest level during the month of June. A new evolution is then noticed and a new peak is noted during the month of August with $45.65 \%$ (Fig. 7).

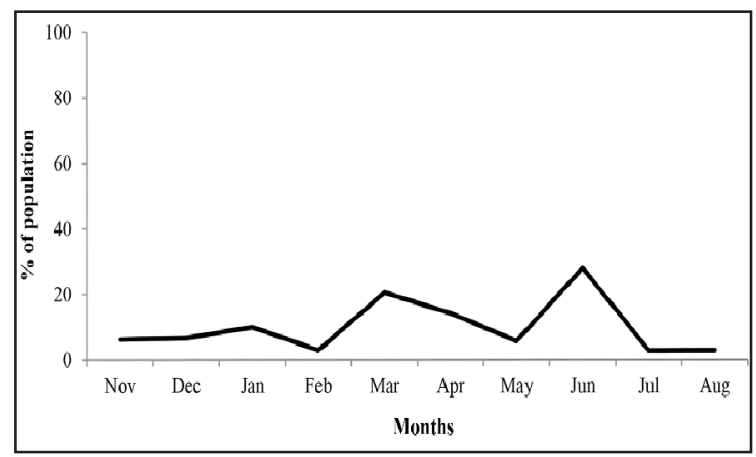

Figure 1. The Overall Fluctuation of $L$. beckii populations on orange trees in the Rouiba region.

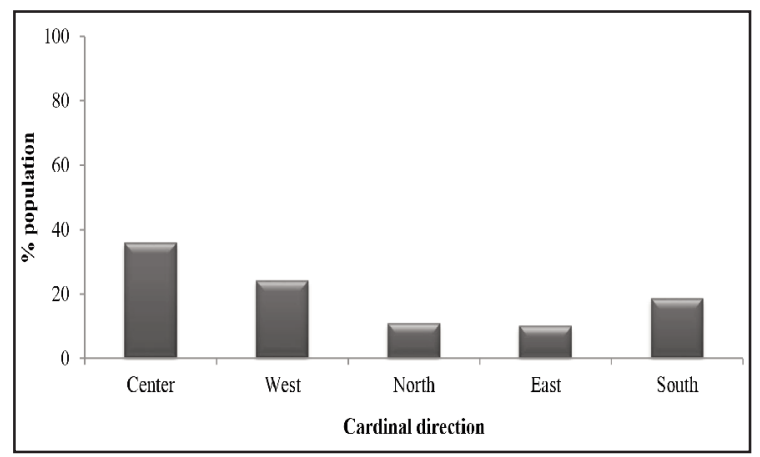

Figure 2. The global Cardinal distribution of L. beckii on orange trees in Rouiba region.

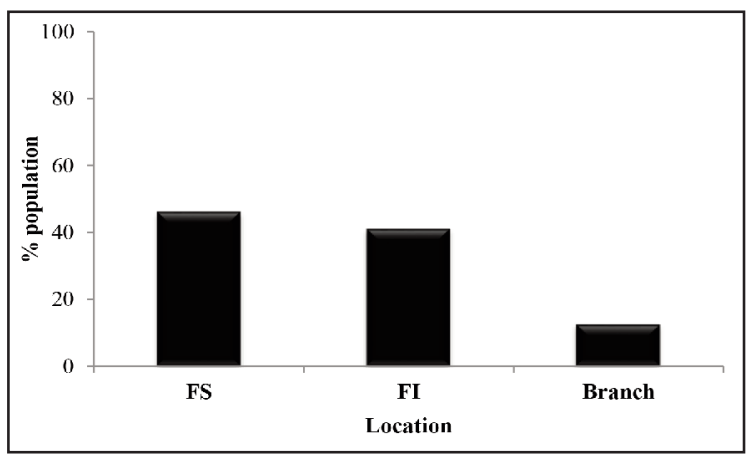

Figure 3. Distribution of the global population of L. beckii on orange trees in Rouiba. 
Once mature, these adults perforate the mealybug shield and search for their hosts to lay their eggs. It is interesting to note that during our observations we counted up to three parasite individuals on the same host, so this parasite is considered a gregarious ectoparasite. When counting, we did not observe adult A. lepidosaphes. The highest percentages are noted during the spring period. Indeed, we note a percentage of $17.54 \%$ during the month of March. There is a significant presence thereafter from April to $\mathrm{Au}$ gust (Fig. 8).

\section{Parasitic incidence}

The overall parasitism rate in L. beckii fluctuates throughout the study period and is around $22.54 \%$. However, this parasitism rate remains very low to control populations of $A$. lepidosaphes. The parasitism rate fluctuations recorded in the insect scale population first pass through a first peak

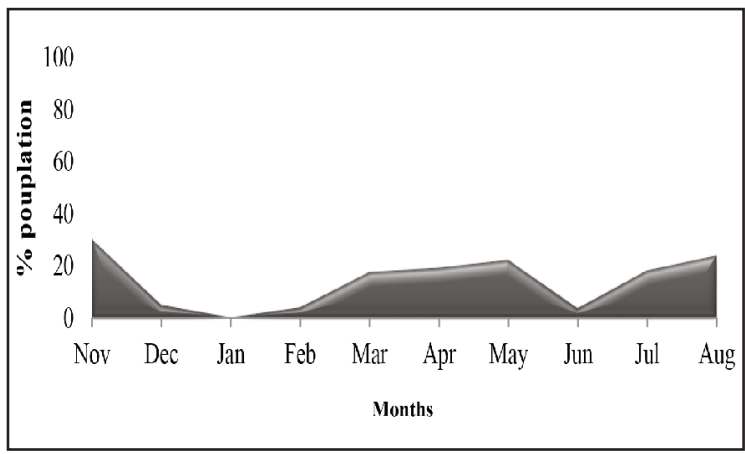

Figure 4. Fluctuation of eggs of $A$. lepidosaphes on L. beckii populations on orange trees in Rouiba.

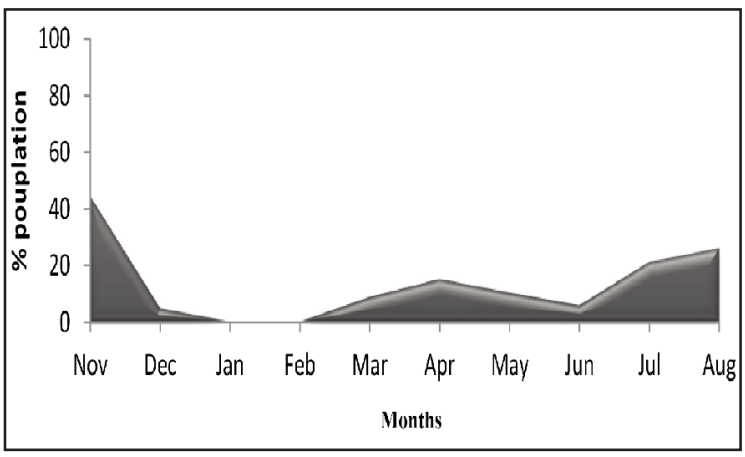

Figure 5. Fluctuation of young larvae of A. lepidosaphes in the populations of L. beckii on orange trees in Rouiba. during the month of March with a rate of $33.39 \%$ and the second peak in June with a parasitism rate of $28.58 \%$ (Fig. 9). Two-way analysis of variance showed that time (months) and orientation had a very highly significant effect on population dynamics and parasite incidence of $L$. beckii $(\mathrm{P}=0.0001$ $<0.001$ ) with $80.2 \%$ of variations in dynamics and $92.6 \%$ of variations in parasite incidence. Also, two-way analysis of variance showed that time (month) and organ have a very highly significant effect on population dynamics and parasite incidence of L. beckii $(\mathrm{P}=0.0001<0.001)$ with $82.4 \%$ of changes in dynamics and $98.4 \%$ of variations in parasite incidence. As for the parasite incidence, the results show that the rate of parasitism in $L$. beckii has improved compared to last year (22.54\%). Aphytis lepidosaphes and Encarsia sp. (Hymenoptera Aphelinidae) have together parasitized up to $32 \%$ of L. beckii (Stathas et al., 2015). The parasite is located much more where the cochineal is in large numbers.

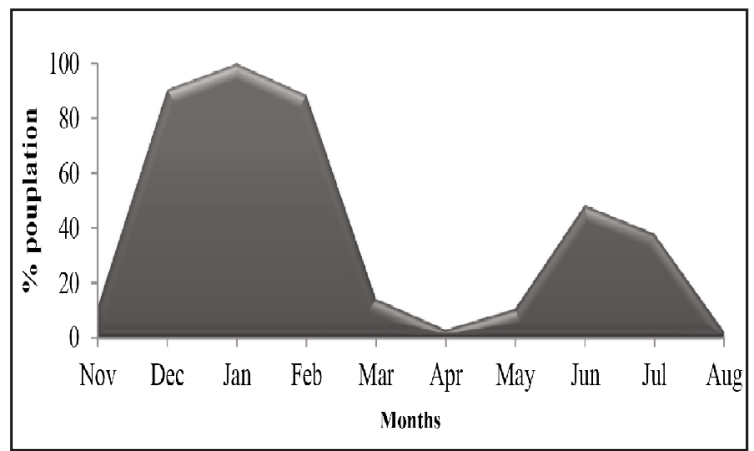

Figure 6. Fluctuation of older larvaes of A. lepidosaphes in the populations of $L$. beckii on orange trees in Rouiba.

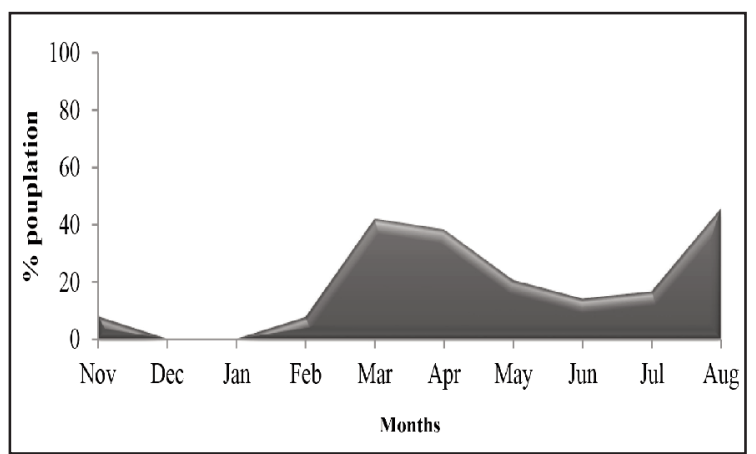

Figure 7. Fluctuation of nymphs of A. lepidosaphes in the populations of $L$. beckii on orange trees in Rouiba. 


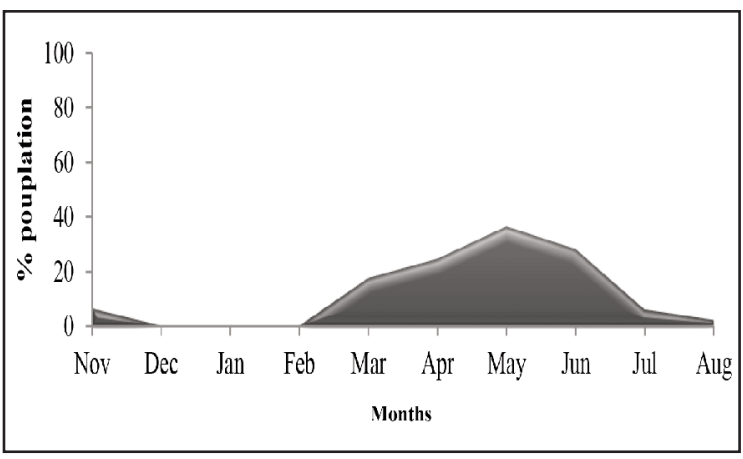

Figure 8. Fluctuation of adults of A. lepidosaphes in the populations of $L$. beckii on orange trees in Rouiba.

The chemical treatments carried out in the orchard certainly contributed to limit the action of these parasites on the populations of the cochineal. Biological control methods should not be considered in isolation, but they have a chance of success in IPM strategies.

\section{CONCLUSIONS}

The results of fluctuations of $A$. lepidosaphes show that this parasitoid overwinters in the form of older larvae in the populations of its host where it develops 3 annual generations: an autumn generation, a spring generation and a summer generation. According to Fabres (1979), in New Caledonia, this parasitoid can develop two or three generations on a generation of its host which presents a great advantage in the use of this parasite in biological control. Aphytis lepidosaphes shows a preference for female stages although males are also attacked but with a low impact compared to that of females. According to Belguendouz (2014) the parasite is active on all organs and has a marked preference for young females.

\section{REFERENCES}

Avidov Z. \& Harpaz I., 1969. Plant Pests of Israel. Israel Universities Press, Jerusalem, 549 pp.

Belguendouz R., 2014. Relations plantes hôtes -cochenilles diaspines sur les agrumes en Algérie: cas de Parlatoria ziziphi Lucas, 1853 (Homoptera: Diaspididae)». Thèse doctorat. École National Supérieure Agronomique, El-Harrach, Alger, 142 pp.

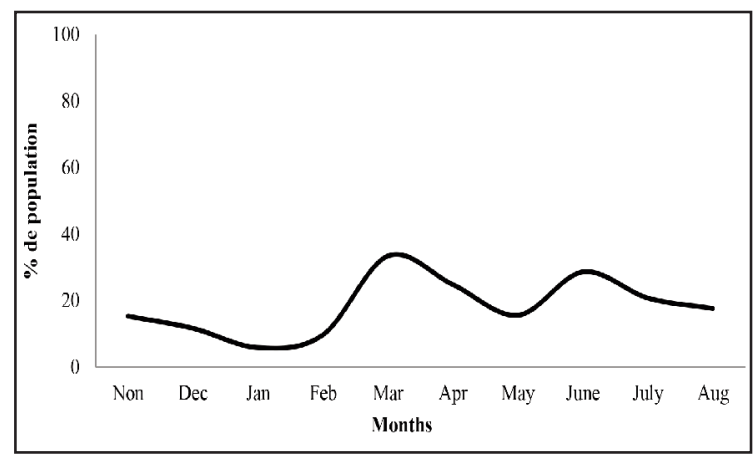

Figure 9. Impact of the global parasitism of A. lepidosaphes on the populations of $L$. beckii on orange trees in Rouiba.

Benassy C., 1961. Les secrétions tégumentaires chez les Coccidés. Annales de Biologie, 37: 165-171.

Benassy C., 1975. Les cochenilles des agrumes dans le basin méditerranéen. Annales de l'Institut national agronomique (El Harrach), 5: 118-142.

Ben-Dov Y., Miller D.R. \& Gibson G., 2014. Scale Net: a database of the scale insect of the Word. Available in: http:/www.sel.barc.usda.gov/scalenet/query.htm [accessed 2 January 2014].

De Villiers J.F., 1998. Citrus mussel scale: Lepidosaphes beckii (Newman) [=Cornuaspis beckii (Newman)]. Citrus pests in the Republic of South Africa. Institute for Tropical and Subtropical Crops, Nelspruit, 288 pp.

Fabres G., 1979. Analyse structurelle et fonctionnelle de la biocénose d'un homoptère (Lepidosaphes beckii, How. Diaspididae) dans deux habitats agrumicoles de la Nouvelle- Calédonie. Ed. ORSTOM, Paris, 222 pp.

Foldi I., 2003. Les cochenilles 2ème partie, Insectes, 130: 27-30.

Kreiter P., Marro J. P. \& Dijoux L., 1998. Le monde mystérieux des Cochenilles. Bulletin de la Société Linnéenne de Lyon, 67: 201-206. https://doi.org/10. 3406/linly.1998.11236

Sforza R., 2008. Les cochenilles sur la vigne in Ravageurs de la vigne, Edition Féret, 389 pp.

Smirnoff W., 1960. Lepidosaphes beckii, Newm. Parasite des agrumes au Maroc, avec description d'une méthode d'étude des cochenilles de la famille des Diaspididae. Les Cahiers de la Recherche Agronomique (Maroc), 10: 37-68.

Stathas G.J, Skouras P.J. \& Kontodimas D.C., 2015. Data on ecology of the purple scale Lepidosaphes beckii (Newman) on citrus in Greece. EPPO Bulletin, 45: 128-132. https://doi.org/10.1111/epp.12184

Vasseur A. \& Schvester D., 1957. Biologie et écologie du Pou de San Jose (Quadraspidiotus perniciosus) en France, Annales des Epiphyties et de Phylogénétique, Institut National de Recherche Agronomique, Paris, 65: 5-161. 
Waterhouse D.F. \& Sands D.P.A., 2001. Classical biological control of arthropods in Australia. ACIAR., 560 pp.

Zuniga S.E., 1971. Biología de la conchuela morada,
Lepidosaphes beckii (Newm.) en trea areas citricolas de Chile (Homoptera: Diaspididae). Revista Peruana de Entomología, 14: 285-290. 